\title{
Administração e Políticas Públicas em Educação: uma revisão sistemática da produção do EnANPAD e do EnAPG de 1997 a 2009
}

\author{
Mirna de Lima Medeiros ${ }^{1}$ \\ Thiago Alves ${ }^{2}$ \\ João Luiz Passador ${ }^{3}$ \\ Cláudia Souza Passador ${ }^{4}$
}

\section{Resumo}

Diante do consenso sobre a importância da educação para o desenvolvimento econômico e social dos países, acredita-se que a administração das escolas e das organizações responsáveis pela gestão das redes de ensino é tema relevante para pesquisas em Administração. Nesse contexto, o objetivo deste artigo é descrever a contribuição do EnANPAD e do EnAPG para a produção de conhecimento sobre administração e políticas públicas da educação básica.Para isso foi realizada uma revisão sistemática nos anais destes eventos referentes ao período de 1997 a 2009. Foram analisados 49 artigos por meio de protocolo que permitiu descrever: características dos trabalhos (distribuição temporal das publicações e as características das autorias); aspectos metodológicos (abordagem e tipologia das pesquisas do ponto de vista acadêmico/científico); e temas abordados. Percebeu-se que a produção está distribuída heterogêneamente no tempo; os autores são em sua maioria vinculados a instituições do Sudeste e Sul do Brasil; há um equilíbrio entre estudos exploratórios e descritivos; e há poucos estudos inferênciais. A abordagem qualitativa é predominante (55\%), contudo, há número representativo de trabalhos quantitativos (35\%). Quanto aos temas, verificou-se que $81,6 \%$ dos artigos se referem a quatro temas principais: desigualdade socioeconômica, financiamento da educação, qualidade do ensino $e$ instrumentos de gestão.

\footnotetext{
${ }^{1}$ Mestre em Administração de Organizações pela Faculdade de Administração, Economia e Contabilidade de Ribeirão Preto - Universidade de São Paulo-USP.End.: Rua Marques da Cruz, 1807-Vila Monte Alegre, Ribeirão Preto-SP.CEP: 14051-150-Brasil.E-mail:mirnamedeiros@hotmail.com.

${ }^{2}$ Doutorando em Administração pela Faculdade de Administração, Economia e Contabilidade da Universidade de São Paulo e Gestor de Finanças e Controle do Estado de Goiás - End.: Rua Horácio Pessini, 350, apt ${ }^{\circ} 33$ - Jardim Nova Aliança, Ribeirão Preto - SP. CEP: $14026-590$ - Brasil. E-mail: thiagoalves@usp.br.

${ }^{3}$ Professor Doutor da Faculdade de Economia Administração e Contabilidade de Ribeirão Preto e Coordenador do Centro de Estudos em Gestão e Políticas Públicas Contemporâneas da USP (GPublic) -Universidade de São Paulo -USP. End.: FEA-RP/RAD. Avenida dos Bandeirantes, 3900 - Ribeirão Preto-SP. CEP.14040-900-Brasil.E-mail: jlpassador@usp.br.

${ }^{4}$ Professora Doutora da Faculdade de Economia Administração e Contabilidade de Ribeirão Preto e Coordenadora do Centro de Estudos em Gestão e Políticas Públicas Contemporâneas da USP (GPublic) - Universidade de São Paulo-USP. End.: FEA-RP/RAD. Avenida dos Bandeirantes, 3900 - Ribeirão Preto -SP. CEP. 14040-900-Brasil. E-mail: cspassador@usp.br.

Artigo recebido em: 25/11/2010. Aceito em: 18/07/2011. Membro do Corpo Editorial Científico responsável pelo processo editorial: Carlos Ricardo Rossetto.
} Esta obra está sob uma Licença Creative Commons Atribuição-Uso. 
Palavras-chave: Educação. Administração. Políticas Públicas. Revisão Sistemática.

\section{Introdução}

Este artigo parte da premissa de que a pesquisa acadêmica é uma atividade fundamental para o desenvolvimento teórico de qualquer disciplina (SOUZA, 1998) e de que o Encontro da Associação Nacional de PósGraduação e Pesquisa em Administração (EnANPAD) e o Encontro de Administração Pública e Governança da mesma associação (EnAPG) são alguns dos mais importantes fóruns de discussão sobre a produção acadêmica em Administração e, especificamente, na Administração Pública no Brasil. Outrossim, acredita-se que os temas mais relevantes para a administração das organizações públicas ou privadas pesquisados nos programas de pósgraduação no país são, de alguma forma, apresentados e debatidos nos eventos que congregam periodicamente os pesquisadores da área.

Ao longo de sua história o EnANPAD tem criado um espaço que comporta discussões teóricas, técnicas e práticas administrativas supostamente aplicáveis a qualquer tipo de organização, mas também se mostra como espaço adequado à apresentação $e$ ao debate de assuntos relativos às áreas específicas da administração (como Marketing, Finanças, Gestão de Pessoas, Tecnologia da Informação, etc.) e de setores cujas organizações adotam práticas específicas para dar conta da natureza de suas operações (Administração Pública, Administração Hospitalar, Administração da Educação, etc.). O EnAPG surgiu, a partir da $27^{a}$ edição do EnANPAD em 2003, como uma iniciativa das divisões acadêmicas de Políticas Públicas e Gestão Pública e Governança apresentando-se como um espaço de divulgação e discussão mais específico. Nesses fóruns, a administração das organizações que se dedicam a prover meios (recursos, pessoas e tecnologias) para que a educação gere seus benefícios à sociedade também têm merecido algum espaço para reflexões, discussões e proposições.

O debate sobre a administração das escolas e dos órgãos responsáveis pela gestão das redes de ensino é fundamental para as sociedades diante do reconhecimento da finalidade da educação no atual momento histórico para as nações. Esse é o estágio atual de uma trajetória percorrida ao longo do 
Século XX, período em que o direito à instrução foi afirmado em inúmeras declarações e se firmou como um consenso geral (TEDESCO, 2002) em decorrência das conquistas no campo dos direitos sociais ocorridas ao longo da história em diferentes momentos e em cada nação. É preciso salientar também que esse consenso atual em torno da educação foi gerado tanto por força das conquistas sociais quanto pela função exercida pela educação no processo de desenvolvimento econômico, na disputa pelos mercados globalizados (KLIKSBERG, 2002), como mecanismo de fortalecimento da democracia (devido à preparação para a cidadania) e como processo de modernização das sociedades (TEDESCO, 2002).

A importância da administração para que as instituições de ensino atinjam seus objetivos passou a ser enfatizada no Brasil desde a década de 1930 a partir dos trabalhos pioneiros de José Querino Ribeiro, de Carneiro Leão e de Lourenço Filho. Considerando que "[...] administração é a utilização racional de recursos para a realização de fins determinados [...]" (PARO, 2002, p. 18), parece razoável considerar que quanto maior for a relevância da finalidade de determinada atividade, maior deve ser a importância dada ao processo administrativo que conduzirá à sua consecução. Dessa forma, uma vez que a finalidade da educação expressa no artigo 205 da Constituição brasileira é o "[...] pleno desenvolvimento da pessoa, seu preparo para o exercício da cidadania e sua qualificação para o trabalho [...]" (BRASIL, 1988, art. 205), é possível afirmar que a administração das organizações responsáveis pela oferta deste serviço, que constitui a garantia de um direito fundamental, é uma questão relevante para a pesquisa em administração. Para traduzir em números a importância da boa gestão das organizações responsáveis pela oferta educação no Brasil, basta dizer que, segundo dados do Censo Escolar realizado pelo Instituto Nacional de Estudos e Pesquisas Educacionais Anísio Teixeira (INEP) do Ministério da Educação (MEC) em 2007, as instituições de ensino brasileiras são responsáveis pela oferta da educação para cerca de 53 milhões de crianças e jovens matriculados nas escolas de educação básica em todo o país.

Diante do contexto, o objetivo deste artigo é descrever a contribuição dos encontros da Associação Nacional de Pós-Graduação e Pesquisa em Administração (EnANPAD) e dos encontros de Administração Pública e Governança da Associação Nacional de PósGraduação e Pesquisa em Administração (EnAPG) para a produção de conhecimento sobre administração e políticas públicas da 
educação básica. Propõe-se: (a) analisar a distribuição temporal dos artigos publicados no período de 1997 a 2009 e verificar se há relação entre os temas abordados com eventos relevantes para a política educacional brasileira no período; (b) verificar a participação dos autores, através da descrição da quantidade de autores que publicaram sobre o tema, a frequência do número de autores por artigo e suas instituições de origem; (c) identificar os aspectos metodológicos dos trabalhos (tipo de abordagem, finalidade e técnicas de pesquisa empregadas); (d) identificar as divisões acadêmicas do EnANPAD que mais discutem os temas investigados; (e) classificar os artigos de acordo com os assuntos e temas investigados em gestão da educação e políticas educacionais.

O artigo apresenta, ainda, uma breve revisão teórica e empírica sobre as políticas educacionais e a gestão da educação. Em seguida são descritas as definições metodológicas que orientaram a análise dos artigos selecionados como objeto de estudo. No terceiro tópico são apresentados os resultados dos aspectos analisados na produção do EnANPAD e EnAPG sobre o tema de interesse e, por fim, são apresentadas algumas considerações diante do que foi percebido.

\section{A Administração e os Desafios da Educação Brasileira}

No Brasil, bem como na maior parte da América Latina, o desafio atual das políticas públicas da educação básica consiste em (a) equalizar as oportunidades educacionais para os alunos de diferentes origens socioeconômicas através da (b) universalização do acesso à educação básica e (c) da oferta do ensino em condições de qualidade. Vale ressaltar que o ensino de qualidade, passível de múltiplos entendimentos (OLIVEIRA; ARAÚJO, 2005; ALMEIDA, 1989; CASASSUS, 2002), é aqui entendido como aquele que possibilita ao aluno aprender o que ele deveria em cada idade e série e que propicia ao aluno as melhores experiências para aquisição de habilidades cognitivas para que seja capaz de se inserir de maneira crítica na sociedade moderna e desempenhe seu papel político, social e econômico (SOARES et al., 2002; FUENZALIDA, 1994).

Contudo, neste início de século ainda há pessoas, sobretudo da geração com mais de 50 anos, saudosas da escola pública do passado. No entanto, é importante lembrar que a "escola boa" do passado era uma escola para 
uma pequena parcela da população. Alguns números ilustram a trajetória de exclusão do processo educacional que a escola do presente, mesmo sem as evidências de qualidade desejáveis, em parte, solucionou. Segundo Almeida (1989), em 1886 apenas 1,8\% da população brasileira tinha acesso à instrução formal. Mais de 50 anos passados daquela época, na década de 1940, a população estudantil havia crescido e era de quase 3,5 milhões para uma população de 41,2 milhões. Essa era a escola do passado. Atualmente, segundo Censo Escolar do INEP/MEC (2007), são mais de 53 milhões de alunos matriculados na educação básica em mais de 200 mil escolas pelo país.

Há também o mito sobre a "escola boa" da atualidade. Nos últimos dez anos o Brasil aperfeiçoou e expandiu o uso de avaliações da educação básica por meio dos testes padronizados de larga escala. Embora o seu uso faça parte de um movimento internacional que visa a melhoria da qualidade do ensino, é preciso considerar que eles têm potencialidades e limitações ${ }^{5}$. Contudo, a publicação na mídia dos resultados desses testes e o índice de aprovação nos cursos mais concorridos das universidades públicas têm criado o mito de que a "escola boa" é a escola privada e que toda escola privada é "boa". Não que a presença no topo dos rankings e a colocação de egressos nos vestibulares concorridos não seja um indicador de qualidade. A crítica a esse mito é que ele considera os testes como indicador de qualidade absoluto (ROTHSTEIN; JACOBSEN, 2008) e o vestibular como o "grande", e não apenas um dos importantes, resultados da educação básica para a sociedade. Além disso (a) ele motiva um grande descrédito ao trabalho da escola pública, (b) desprestígio para as políticas e pesquisas sobre a educação pública, (c) não leva em conta que as escolas privadas atendem apenas $12 \%$ das matrículas da educação básica em todo o Brasil e (d) não considera que o valor da mensalidade das escolas privadas, que passam a ser cobiçadas por constarem no topo dos rankings, equivalem, muitas vezes, ao gasto anual do estado para manter um aluno na escola pública (um exemplo é, segundo Pinho, Góis e Takahashi (2010), o Colégio Vértice de São Paulo, $1^{\circ}$ lugar no ENEM em 2009, que cobra uma mensalidade de $\mathrm{R} \$ 2.756)$.

Nessa questão do público e do privado na educação brasileira, é importante frisar que nem sempre a escola privada oferece melhor infraestrutura para o ensino. Segundo o Censo Escolar 2007, apenas 57,2\% das escolas da rede privada possuem bibliotecas, $38,4 \%$ possuem quadra de esporte, $38,9 \%$ possuem laboratório de informática e 17,3\% possuem laboratórios de ciên-

${ }^{5}$ Uma análise de potenciais e limitações dos testes de larga escala pode ser vista em Rothstein e Jacobsen (2008). 
cias (números inferiores aos das escolas das redes estaduais e redes federais que atendem mais de $40 \%$ das matrículas da educação básica). Ou seja, há escolas e escolas privadas. Esse quadro, somado aos números da Pesquisa Nacional por Amostra de Domicílio (PNAD) em 2007 que mostra que 74,5\% da população brasileira tem renda per capita domiciliar inferior a $\mathrm{R} \$ 500$ (sendo 15,8\% inferior a $\mathrm{R} \$ 100$ ) e apenas 9,9\% tem renda per capita domiciar acima de $\mathrm{R} \$ 1.000$, evidencia que a solução para os problemas educacionais da população deve vir do setor público e que a "escola boa" tem que ser a escola pública destinada ao atendimento de toda a população, independente do nível socioecômico das famílias.

Sobre o desafio e o "percurso" da universalização do ensino, os dados da PNAD em 2008 mostram que embora tenha havido grande avanço, sobretudo nas últimas três décadas, o desafio da universalização continua, pois ainda falta matricular mais de 3,9 milhões de alunos que compõem a população brasileira de 4 a 17 anos e que estão fora da escola 6 . O Gráfico 1 mostra que na faixa etária dos 7 aos 14 anos resta $2,1 \%$ da população para matricular. Embora seja um percentual pequeno, ele representa quase $572 \mathrm{mil}$ crianças e adolescentes fora da escola. Na etapa do ensino médio (15 a 17 anos), os esforços deverão ser maiores, pois, ainda faltam quase $16 \%$ (ou 1,63 milhão) de jovens da população entre 15 e 17 anos para se matricular. O desafio é ainda maior quando se trata da educação infantil. Na faixa de 4 a 6 anos, 20,2\% da população não frequenta a escola. Nos primeiros anos da educação infantil (até os 3 anos), o Brasil precisa mais do que quintuplicar o número de matrículas atuais, pois apenas $18,1 \%$ da população é atendida.

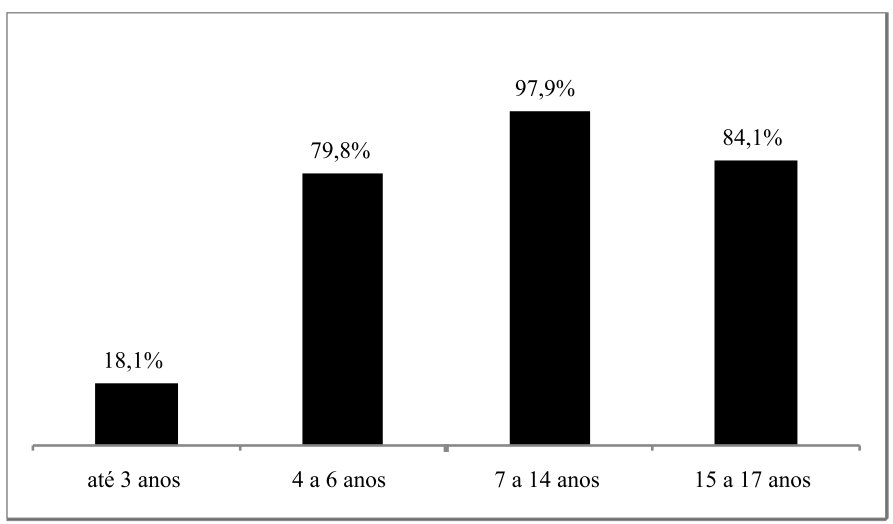

Gráfico 1: Brasil 2007 - Taxa de atendimento educacional por faixa etária Fonte: Elaborado a partir de PNAD/IBGE (2008)

${ }^{6} \mathrm{~A}$ Emenda Constitucional n. 59 de 11 de novembro de 2009 estabelece a obrigatoriedade do ensino para a população brasileira com idade entre 4 e 17 anos (BRASIL, 2009). 
Esse primeiro desafio é apenas quantitativo, mas fundamental para a compreensão dos problemas administrativos em que se envolve o setor educacional brasileiro, principalmente quando se fala em educação pública, pois $88 \%$ das matrículas da educação básica no Brasil são oferecidas pelo setor público.

Quanto ao desafio da qualidade, do mesmo modo que não se pode mais admitir restrição de acesso ao ensino (Gráfico 1), também não se pode considerar que um sistema educacional em que $22,2 \%$ dos alunos da $4^{a}$ série ainda não foram alfabetizados e $36,8 \%$ só sabem ler frases simples e de maneira insatisfatória (RIBEIRO; RIBEIRO; GUSMÃO, 2005). A qualidade como horizonte da política de Estado concebe a educação como instrumento insubstituível à coesão política, à geração do capital social, à construção da nacionalidade, ao crescimento econômico, à democracia, à manutenção da estrutura social do país (saúde, habitação e demais serviços básicos) e à provisão de pessoal qualificado para a realização de projetos em áreas distintas relacionadas ao crescimento e ao desenvolvimento. Sob essa ótica, a qualidade propõe que o sistema escolar possibilite a formação de indivíduos para uma sociedade com valores e comportamentos requeridos pelas novas demandas sociais relacionadas a questões como meio ambiente, paz, pluralidade étnica, direitos humanos e superação da pobreza. (FUENZALIDA, 1994; CASASSUS, 2002).

O terceiro desafio está relacionado ao fato do Brasil ser um país muito desigual e figurar em nono lugar em desigualdade numa lista de 134 países num ranking formado pelo Índice de Gini ${ }^{7}$. Para Huitrón (2002), a desigualdade de caráter socioeconômico é causada pela desigualdade educacional (desigualdade de acesso e/ou qualidade do ensino percebido). Essa afirmação, entre outras evidências empíricas, está ancorada pela teoria econômica que sugere que o nível de renda dos indivíduos numa sociedade em que vige a economia da informação e do conhecimento é determinado por suas habilidades produtivas e que esta, por sua vez, é determinada pelo nível de educação. Sendo assim, caso a qualidade da educação seja estratificada em classes sociais e correlacionada com o nível de renda das famílias dos estudantes, o resultado será um sistema educacional atuando como reprodutor da seleção econômica e social vigente desde o Século XIX na sociedade brasileira (ALMEIDA, 1989).

${ }^{7} \mathrm{O}$ Índice de Gini mede a distribuição de renda entre os indivíduos de um país. 
Assim, é possível perceber a estreita relação entre os desafios da quantidade (acesso), qualidade e equidade, uma vez que a educação (de qualidade) é vista como um instrumento para a diminuição da desigualdade e que a distribuição equitativa de conhecimento, habilidades e valores podem permitir uma melhor participação de crianças e jovens pobres na vida social (CASASSUS, 2002).

Em que pese as questões de natureza política e financeira a serem resolvidas para a solução dos problemas contemporâneos da educação no Brasil já mencionados, há também aspectos relacionados à gestão das mais de 200 mil unidades de ensino e das Secretarias de Educação e dos demais órgãos gestores das redes para serem aprimorados. No âmbito macro (políticas, planejamento, organização, estratégias e avaliação de sistemas) e micro (administração do esforço pedagógico das escolas), a administração deve atuar como processo racional para coordenar esforços de pessoas e a utilização de recursos para que a educação atinja seus objetivos (PARO, 2002). Inúmeros estudos a partir de 1930 reconheceram a educação como área de ação para os administradores que devem atuar no planejamento, na organização, na formulação de estratégias e na avaliação de instituições e sistemas de ensino.

Para Souza (2007) é possível demarcar três grandes períodos no desenvolvimento do conhecimento em gestão da educação. O primeiro compreendeu as décadas de 1930 e 1970. Esse período foi marcado pela influência de autores americanos e tem a administração da educação como uma especialização da Teoria Geral da Administração (TGA). O segundo iniciado na década de 1970 e melhor definido na década de 1980 foi marcado pela postura crítica em relação ao primeiro período. Nessa época, a administração da educação rompeu com os princípios administrativos derivados da escola clássica e da escola comportamental da administração por defender que tais princípios não são aplicáveis aos fins das organizações de ensino que não poderiam estar alinhadas à eficiência econômica e à eficácia organizacional sugerida pelos princípios da TGA. Para os autores deste período, os princípios da TGA confiam "[...] reduzida atenção aos valores éticos, às aspirações políticas e à dimensão humana da gestão da educação" (SANDER, 2007, p. 14). O terceiro período está em curso, mas, segundo Souza (2007), esse período tende a desenvolver-se mais próximo dos estudos mais críticos do segundo período.

Nesse contexto de definição de um campo teórico para a administração da educação, percebe-se no trabalho de Pereira e Andrade (2005) e Sander (2007) que a produção acadêmica no âmbito da pós-graduação em educa- 
ção no Brasil tem se caracterizado por uma orientação sócio-histórica de base marxista, fenomenológica, existencialista e anarquista. Atualmente no Brasil, não há grande interação dos pesquisadores das escolas de administração e de educação quando se trata da investigação de fenômenos administrativos que ocorrem nas organizações de ensino. A diferença da base epistemológica das pesquisas nessas duas áreas do conhecimento pode ser uma das possíveis explicações para tal fenômeno.

Apesar das diferenças, diante da grande complexidade que se apresenta nos desafios impostos à educação no país, acredita-se que esforços conjuntos de diversas áreas do conhecimento, tais como Educação, Administração, Contabilidade, Economia, Ciências Sociais entre outros, poderiam colaborar para a construção do conhecimento sobre administração dos sistemas públicos de ensino. Casanova (2006 apud FADUL; SILVA, 2009) e Fourez (1995 apud FADUL; SILVA, 2009) corroboram esse pensamento, pois consideram que a inter, a multi e a transdisciplinaridade são mais adequadas do que a unidisciplinaridade para a abordagem da realidade contemporânea, pois, enquanto as abordagens inter, multi e transdisciplinares compreendem essa realidade como algo complexo, as disciplinares a reduzem a algo simples.

\section{Aspectos Metodológicos}

O artigo foi desenvolvido por meio de uma revisão sistemática dos anais do EnANPAD e do EnAPG. De acordo com Clarke (2001), revisões sistemáticas utilizam-se de métodos sistemáticos e explícitos para identificar, selecionar e avaliar criticamente pesquisas relevantes, coletar e analisar dados dos estudos incluídos na revisão. São particularmente úteis para integrar as informações de um conjunto de estudos realizados separadamente sobre determinado assunto, identificando temas que necessitam de evidência $e$ auxiliando na orientação para investigações futuras. Ao viabilizarem, de forma clara e explícita, um resumo dos estudos sobre certo tema, as revisões sistemáticas permitem a incorporação de espectro maior de resultados relevantes, ao invés de limitar as conclusões à leitura de alguns artigos.

Esta revisão analisou artigos apresentados no EnANPAD e no EnAPG disponíveis para consulta no site da associação (http://www.anpad.org.br/ busca_avancada.php) por meio das seguintes palavras-chave: administração da educação; políticas educacionais; gestão escolar; educação básica; ensi- 
no básico; instituições de ensino; e organização escolar. Contudo, a pesquisa por palavras compostas foi inócua e não encontrou nenhum artigo. Verificou-se que o sistema de busca identificava artigos somente através de palavras simples. A segunda tentativa foi bem-sucedida e encontrou 1.590 artigos $^{8}$ por meio das palavras: educação (137); ensino (374); políticas (158); educacionais (13); escolar (11); e escola (1.008).

$\mathrm{Na}$ primeira análise dos artigos encontrados, percebeu-se que a base de dados, mesmo com a seleção de eventos específicos, encontrou artigos de outros eventos da ANPAD. Essa ocorrência adicionou mais um critério de seleção para os artigos. Cinco foram os critérios utilizados: (a) evento: EnANPAD ou EnAPG; (b) ano de publicação: período de 1997 a 2009; (c) tema: política educacional ou gestão de organizações de ensino; (d) nível de ensino: educação básica; e (e) setor das instituições de ensino: educação pública. Foram selecionados 49 artigos (sendo 37 do EnANPAD e 12 do EnAPG), após a exclusão dos artigos que não atenderam a esses critérios. A Figura 1 apresenta o fluxo de seleção dos artigos.

Os artigos selecionados foram analisados por meio de um protocolo cuja finalidade era descrever três aspectos. O primeiro refere-se às características dos trabalhos. Nesse aspecto descreveu-se a distribuição temporal das publicações e as características das autorias. O segundo diz respeito aos aspectos metodológicos e analisou o tipo de abordagem de pesquisa e a finalidade (do ponto de visa acadêmico/científico) dos artigos. No terceiro foi realizada uma análise dos temas abordados. Inicialmente foram identificadas as divisões acadêmicas do EnANPAD que mais discutem sobre políticas e gestão da educação pública. Em seguida foram identificados os temas mais abordados nos trabalhos de ambos os eventos. Esse procedimento foi baseado na indicação dos assuntos mais recorrentes apontados pelas pesquisas sobre gestão e políticas da educação no Brasil nos periódicos, dissertações e teses produzidas na área de educação desde a década de 1980, segundo Souza (2007), Castro e Werle (2004) e Oliveira (2006). A análise da produção do tema de interesse no âmbito das pós-graduações em administração a partir dos temas mais investigados pelos pesquisadores da área da educação visa analisar o interesse de pesquisas sobre esses temas comuns às áreas e as diferenças e similitudes na percepção dos desafios da educação brasileira.

${ }^{8}$ Alguns artigos foram encontrados quando pesquisados em mais de uma palavra-chave. O número total de artigos encontrados não considera os artigos duplicados (111). 


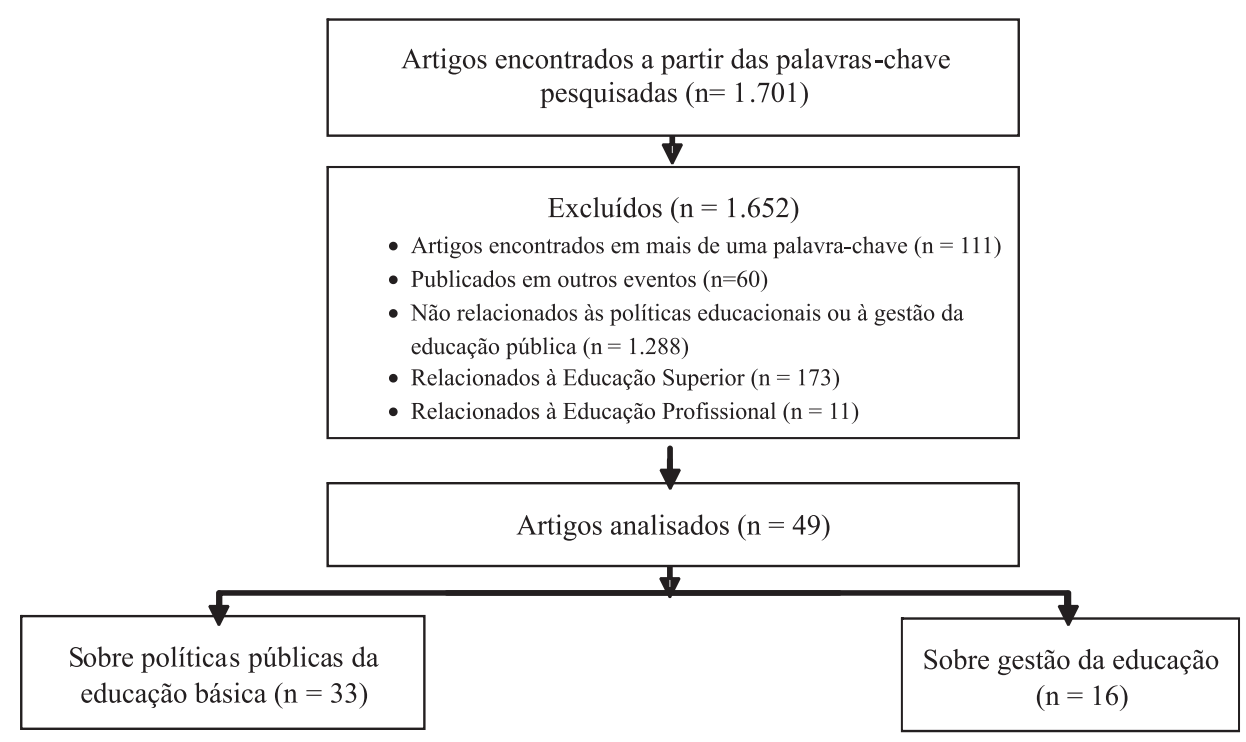

Figura 1: Fluxo de seleção de artigos

Fonte: Elaborado a partir dos Anais do EnANPAD e EnAPG de 1997 a 2009

\section{Análise dos Artigos}

\subsection{Caracterização dos Trabalhos}

Observou-se que 99 autores são responsáveis pelos 49 artigos analisados. Desses autores, foi possível perceber que somente sete participaram na elaboração de mais de um trabalho: cinco colaboraram em dois e apenas duas autoras colaboraram com mais de dois (sendo que uma esteve engajada em sete artigos e outra em quatro). Esse aspecto pode indicar que não há continuidade nas pesquisas sobre o tema por grande parte dos autores.

Dos trabalhos publicados nos encontros, $51 \%$ foram escritos por dois autores, $18 \%$ por três autores, $19 \%$ por um único autor, $8 \%$ por quatro autores e apenas $2 \%$ por cinco e seis autores. A maioria dos trabalhos elaborados em dupla possui autores de uma mesma instituição, o que pode significar trabalhos que são fruto de parcerias estabelecidas intrainstitucionalmente. O baixo número de trabalhos elaborados por mais de três autores (12\%) pode indicar que não há muitos grupos de pesquisa ou de estudos que discutem sobre a temática e, em equipe, que elaboram comunicações científicas. 
Foram encontrados trabalhos provenientes de 30 instituições. As que têm maior participação em termos de filiação de autores dos trabalhos analisados são: EAESP/FGV (17\%), EBAPE/FGV (12\%), FJP (08\%), USP (6\%) e UFRGS e PUC-PR (5\% cada). Nota-se que a soma da produção das seis instituições listadas é superior a $50 \%$ da produção total analisada, o que leva a supor que essas instituições mantêm linhas de pesquisa, grupos de estudo ou disciplinas que despertem o interesse em relação à temática. Nota-se que as cinco instituições com maior número de filiação de autores estão inseridas nas regiões Sudeste e Sul do País. Quando somadas às demais instituições, a predominância dessas regiões se torna ainda mais significativa na produção acadêmica da área: o Sudeste detém $63 \%$ dos autores, o Sul 25\%, o Nordeste $8 \%$, o Norte e o Centro-oeste $2 \%$ cada.

Os trabalhos não possuem distribuição homogênea quanto às instituições e tampouco em relação ao número de artigos publicados em cada um dos anos. Na Figura 2 pode-se observar um gráfico da distribuição temporal dos artigos. Percebe-se que há um aumento no número de artigos públicados a partir do ano de 2006 e que nos anos em que os dois eventos ocorrem há um maior número de artigos sobre a temática. Um fato positivo para a temática é que, em ambos os eventos, houve um crescimento ou manutenção do número de trabalhos: no EnAPG, a partir de 2004, foram encontrados 2, 4 e 6 trabalhos em suas edições; já no EnANPAD foram encontrados 6, 7, 6 e 6 trabalhos nas edições a partir de 2006. Tal fato pode indicar que há um maior interesse em questões de gestão e políticas do ensino básico nesses eventos.

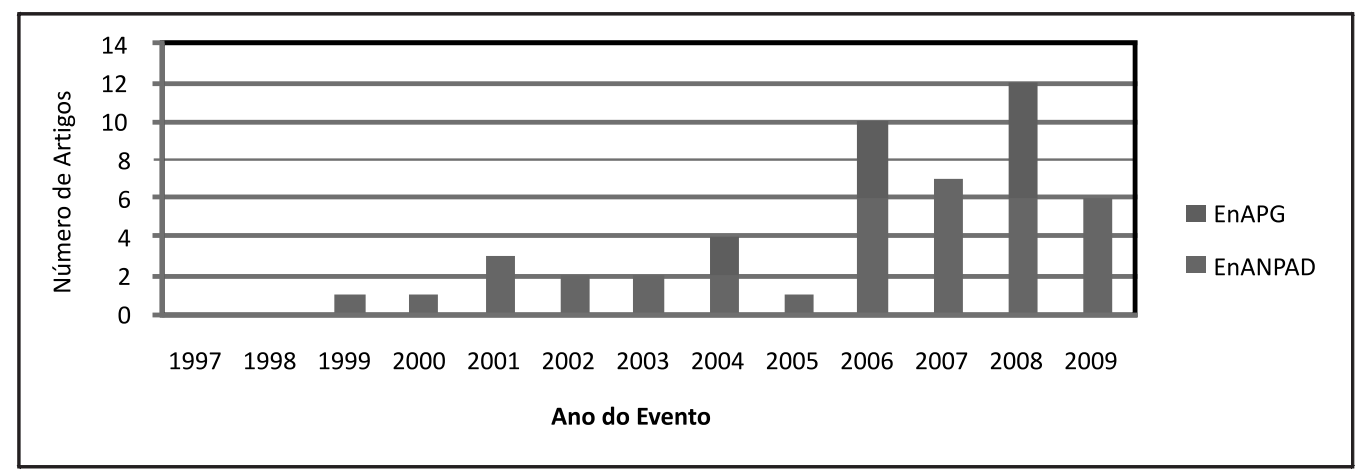

Figura 2: Número de Artigos por Ano

Fonte: Elaborado a partir dos Anais do EnANPAD e EnAPG de 1997 a 2009

No geral, os artigos não se relacionam muito estreitamente com eventos relevantes para a política educacional brasileira no período (tais como 
um novo plano educacional nacional, ou uma nova lei que muda parâmetros de financiamento ou avaliação do ensino). Contudo, há trabalhos como o de Thimoteo e Gomes (2001) que avalia o efeito das políticas de financimento (FUNDEF) e avaliação (SAEB), conjuntamente três anos após a entrada em vigor do fundo que inaugurou uma nova fase do financiamento da educação básica; numa tentativa de avaliar os impactos da nova política de financiamento, Sobreira e Campos (2006) realizaram uma simulação da proposta de emenda constitucional que criou o FUNDEB a partir de 2007; e Campos e Cruz (2007) trataram de analisar os primeiros impactos do FUNDEB no EnANPAD no mesmo ano em que o novo fundo entrou em vigência.

\subsection{Aspectos Metodológicos dos Artigos Analisados}

O tipo de abordagem $e$ as escolhas metodológicas que delineiam as pesquisas dependem do pesquisador e do problema de pesquisa. A análise das estratégias de investigação pelo qual os autores optam podem informar que tipo de conhecimento está sendo produzido sobre a temática em questão. Além disso, o que distingue a ciência como forma particular de construção da realidade é o uso sistemático do método científico. Sendo assim, é relevante em uma análise da produção acadêmica, observar de qual ferramental os pesquisadores tem se valido. Devido às limitações de espaço, optou-se por classificar os artigos segundo a natureza do método (aborda$\mathrm{gem}$ ) e de acordo com a finalidade de pesquisa. Ademais, foram listadas as técnicas de pesquisa utilizadas.

Para delimitação das pesquisas quanto aos fins, optou-se pela classificação em quatro categorias: exploratória, descritiva, explicativa (ou inferencial) e intervencionista. A pesquisa exploratória busca uma visão geral, maior familiaridade ou aprofundamento inicial acerca de determinado fato ou tema. A descritiva tem como objetivo conhecer, caracterizar e interpretar a realidade sem nela interferir para modificá-la; pode se interessar pelas relações entre as variáveis, contudo não tem compromisso de explicá-los, embora sirva de base para tal explicação. A inferencial busca esclarecer os fatores que contribuem para a ocorrência de determinado fenômeno, estabelecendo relações de causa e efeito. Já a intervencionista visa não apenas explicar, mas também interferir na realidade estudada com vista a alterá-la. Verificou-se certo equilíbrio entre as pesquisas exploratórias e descritivas (43\% de cada 
tipo) nos trabalhos analisados. Há ainda $14 \%$ que se referem a artigos de cunho explicativo e não houve ocorrência de pesquisas intervencionistas.

A abordagem utilizada pelos autores pode ser classificada como qualitativa, quantitativa ou uma combinação entre as duas abordagens. Dos 49 artigos, a maioria (55\% do total) possui abordagem qualitativa, 17 deles (35\%) utilizaram técnicas quantitativas e cinco utilizaram simultaneamente métodos qualitativos e quantitativos (10\%). Quanto às técnicas de pesquisa, observou-se predominância dos estudos de caso (opção em 19 artigos) na abordagem qualitativa e das técnicas de correlação e regressão (em seis e em quatro trabalhos respectivamente) na quantitativa. Além dessas, foi verificado o uso de outras técnicas como pesquisa bibliográfica, etnografia; técnicas estatísticas uni e multivariadas como análise de variância, análise fatorial e análise de conglomerados; bem como técnicas econométricas como decomposição de Oxaca, curva Parada de Pen, painel de efeitos fixos, etc.

\subsection{Tema dos Artigos}

Na primeira categorização, optou-se pela classificação dos trabalhos do EnANPAD nas 11 divisões acadêmicas do evento em 2010. Dos 37 artigos, um se enquadra na divisão "Administração da Informação", dois na "Estratégia em Organizações", três na "Estudos Organizacionais" e 31 na "Administração Pública" (APB). Como seria esperado, é nítida a predominância de artigos que tratam da Educação Básica Pública na área de Administração Pública. A discussão do tema de interesse nas sessões de APB corrobora o que Sander (2007) afirma quanto à estreita relação no desenvolvimento das áreas de conhecimento da administração pública e da administração da educação no Brasil a partir de 1930. O fato também corroborou para confirmação da escolha do EnAPG como segundo evento para análise.

Em relação à área temática, os artigos foram classificados primeiramente em dois grandes grupos: gestão da educação e política educacional. Em seguida, os temas relacionados foram subdivididos. Os que tratam de gestão da educação foram alocados em temas com base no trabalho de Souza (2007) que analisou 516 teses e dissertações produzidas no âmbito das pós-graduações em educação sobre o tema no período de 1987 e 2005. Neste estudo, os temas mais pesquisados foram: (a) Diretor/gestor escolar, (b) Formação, prática e desafios do diretor escolar, (c) Gestão democrática, (d) Instrumentos de Gestão, (e) Conselho Escolar. Os temas sobre as políticas 
educacionais foram baseados no trabalho de Oliveira (2006) que abordou os desafios recentes dessa área de atuação do Estado. São eles: (a) Desigualdade/equalização das oportunidade educacionais; (b) Investimento/Financiamento da educação; (c) Qualidade do ensino; (d) Garantia do direiro à educação; (e) Descentralização das políticas públicas; e (f) Estado e educação. $\mathrm{O}$ Gráfico 2 apresenta os temas mais abordados nos 49 artigos analisados e o Quadro 1 apresenta os trabalhos no formato autor-data em cada tema: 16 deles se referem aos temas relacionados à gestão da educação e 33 são sobre políticas educacionais (Quadro 1 ).

No Gráfico 2 percebe-se que, dos artigos em gestão, quase $50 \%$ versam sobre instrumentos de gestão. Os nove trabalhos (ver Quadro 1) abordam ferramentas e técnicas de gestão como análise de estrutura organizacional, modelagem organizacional, planejamento estratégico, Business Intelligence, certificação ocupacional, qualidade total, gestão de ambientes virtuais em educação, tecnologia da informação (TI) e gestão por resultados. De certa forma, os modelos analisados e/ou propostos nesses trabalhos são originários da administração de empresas que são comumente transpostos para a administração pública. Essa transposição, apesar de ser amplamente utilizada e, muitas vezes, recomendada como estratégica para solucionar as supostas "ineficiências" do setor público - como em Osborne e Gaebler (1995) - tem sido alvo de críticas (SANDER, 2007; PAULA, 2005).

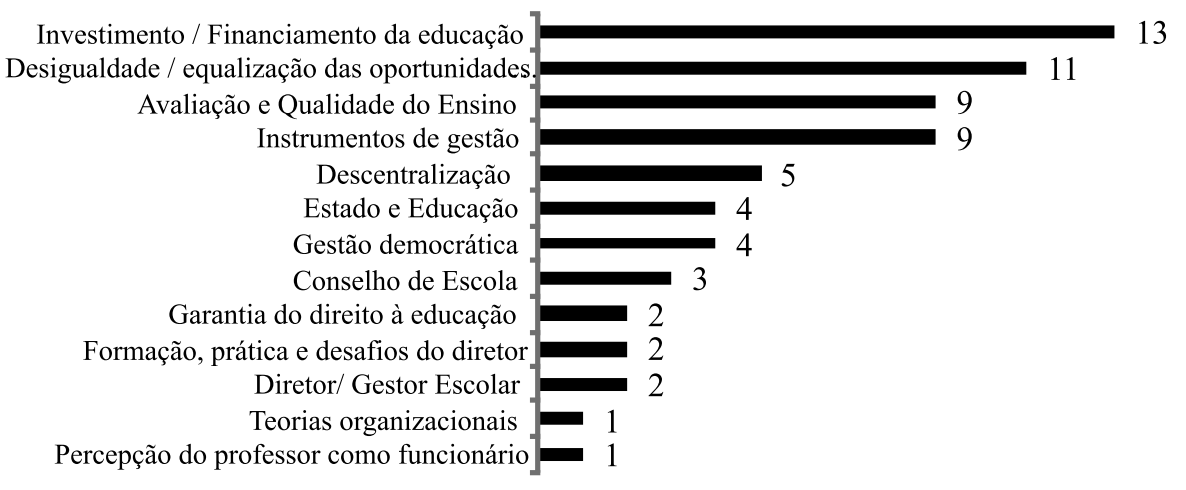

Gráfico 2: Distribuição das temáticas dos artigos

Fonte: Elaborado a partir dos Anais do EnANPAD e EnAPG de 1997 a 2009 


\begin{tabular}{|c|c|c|c|c|}
\hline Assunto & Tema & Autor (Data) & $\begin{array}{l}\text { Número de } \\
\text { artigos (1) }\end{array}$ & $\begin{array}{l}\text { Frequência } \\
\text { relativa (2) }\end{array}$ \\
\hline \multirow{7}{*}{$\begin{array}{l}\text { Gestão das } \\
\text { instituições } \\
\text { de ensino }\end{array}$} & Diretor/ Gestor Escolar & Teixeira (2008); Galvão e Cavalcanti (2009) & 2 & $4,1 \%$ \\
\hline & $\begin{array}{l}\text { Formação, prática e } \\
\text { desafios do diretor }\end{array}$ & Takahashi e Machado-da-Silva (2002); Galvão e Cavalcanti (2009) & 2 & $4,1 \%$ \\
\hline & $\begin{array}{l}\text { Percepção do professor } \\
\text { como funcionário }\end{array}$ & Costa e Salm (2006) & 1 & $2,0 \%$ \\
\hline & Teorias organizacionais & Souza e Prado (2009) & 1 & $2,0 \%$ \\
\hline & Gestão democrática & $\begin{array}{c}\text { Jesus e Santos (2007); Sucupira . (2007); Leite (2004); } \\
\text { Reinaldo e Brito (2008) }\end{array}$ & 4 & $8,2 \%$ \\
\hline & Conselho de Escola & $\begin{array}{l}\text { Jesus e Santos (2007); Sucupira et al. (2007); Reinaldo e Brito } \\
\qquad(2008)\end{array}$ & 3 & $6,1 \%$ \\
\hline & Instrumentos de gestão & $\begin{array}{c}\text { Vieira et al. (2000); Vieira e Cardoso (2001); Leite (2004); Bonse et } \\
\text { al. (2006); Reis e Angeloni (2006); Teixeira (2008); Almeida, } \\
\text { Junquilho e Novaes (2008); Löbler et al. (2008); Pereira, Miranda- } \\
\text { Ribeiro e Campos (2009) }\end{array}$ & 9 & $18,4 \%$ \\
\hline \multirow{6}{*}{$\begin{array}{l}\text { Políticas } \\
\text { Educacionais }\end{array}$} & Estado e Educação & $\begin{array}{c}\text { Gonçalves, Gonçalves e Augusto (2004); Duarte e Leite (2006); } \\
\text { Prado e Cruz (2006); Borges (2008) }\end{array}$ & 4 & $8,2 \%$ \\
\hline & $\begin{array}{c}\begin{array}{c}\text { Garantia do direito à } \\
\text { educação }\end{array} \\
\end{array}$ & Campos e Cruz (2007); Gonçalvez Júnio e Simielli (2007) & 2 & $4,1 \%$ \\
\hline & Descentralização & $\begin{array}{l}\text { Takahashi (2003); Lotta e Martins (2004); Sumiya e Franzese } \\
\text { (2004); Alves, Passador e Matias (2006); Bueno, Pinheiro e } \\
\text { Pereira (2007) }\end{array}$ & 5 & $10,2 \%$ \\
\hline & $\begin{array}{l}\text { Avaliação e Qualidade } \\
\text { do Ensino }\end{array}$ & $\begin{array}{l}\text { Andrade, Ussan e Klering (2001); Thimoteo e Gomes (2001); Reis e } \\
\text { Angeloni (2006); Teixeira e Higuchi (2006); Campos e Cruz (2007); } \\
\text { Gonçalvez Júnio e Simielli (2007); Fernandes et al. (2008); Santos, } \\
\text { Souza e Galindo (2008); Pereira (2009) }\end{array}$ & 9 & $18,4 \%$ \\
\hline & $\begin{array}{l}\text { Investimento / } \\
\text { Financiamento da } \\
\text { educação }\end{array}$ & $\begin{array}{l}\text { Thimoteo e Gomes (2001); Sumiya e Franzese (2004); Alves, } \\
\text { Passador e Matias (2006); Costa e Duarte (2006); Sobreira e } \\
\text { Campos (2006); Bacelos e De-Medeiros (2007); Campos e Cruz } \\
\text { (2007); Gonçalvez Júnio e Simielli (2007); Borges (2008); Klein } \\
\text { (2008); Moriconi e Marconi (2008); Zoghbi e Arvate (2008); Silva } \\
\text { Neto e Ribeiro (2009) }\end{array}$ & 13 & $26,5 \%$ \\
\hline & $\begin{array}{l}\text { Desigualdade / } \\
\text { equalização das } \\
\text { oportunidades } \\
\text { educacionais }\end{array}$ & $\begin{array}{c}\text { Campos e Cruz (2007); Thimoteo e Gomes (2001); Leite (2002); } \\
\text { Scarpin e Scarpin (2006); Leite (2008); Westin et al. (2008); Leite e } \\
\text { Braga (2009); Silva Neto e Ribeiro (2009); Craveiro e Farah (2005); } \\
\text { Basso (1999); Veiga, Leite e Duarte (2003) }\end{array}$ & 11 & $22,4 \%$ \\
\hline
\end{tabular}

(1) Um artigo pode ser classificado em mais de um tema.

(2) A frequência relativa dos artigos refere-se ao total de artigos analisados (49) e não ao total de artigos por tema.

Quadro 1: Classificação dos artigos por tema

Fonte: Elaborado a partir dos Anais do EnANPAD e EnAPG de 1997 a 2009

Ainda entre os artigos sobre gestão, os de Jesus e Santos (2007), Sucupira et al. (2007) e Reinaldo e Brito (2008) abordam os temas Conselho de Escola e Gestão Democrática e estão relacionados à dimensão política e à relação de poder nas escolas. O trabalho de Sucupira et al. (2007) captou, por meio de entrevistas, o desinteresse ou a desinformação de membros (pais, alunos e funcionários) de uma comunidade escolar da Baixa Fluminense sobre a existência e a função dos conselhos de escola. Jesus e Santos (2007) constataram que há obstáculos objetivos e subjetivos para a efetiva participação dos membros das comunidades escolares na elaboração e acompanhamento do Plano de Desenvolvimento da Escola nas escolas municipais de Salvador e que o processo decisório na maioria dos casos está 
concentrado no gestor escolar. Já Reinaldo e Brito (2008) avaliam a contribuição do conselho escolar para melhoria da gestão de uma escolha por meio da percepção dos seus componentes (professores, funcionários, pais e alunos) e apontam que a atuação do conselho é uma forte contribuição para a implantação da gestão democrática no âmbito da escola.

Os temas referentes à função, à formação, à prática e aos desafios do diretor escolar foram contemplados em três artigos. Eles tratam sobre as competências requeridas pelos gestores para exercerem suas atribuições e as pressões ambientais sofridas, bem como a importância da liderança, da qualificação, dos recursos e conhecimentos para o exercício da gestão escolar.

Dois artigos não foram classificados nos temas de gestão escolar previamente definidos com base em Souza (2007). Um deles é de Souza e Prado (2009), o trabalho desses autores faz um esforço de compreensão da realidade das organizações escolares por meio de metáforas das imagens das escolas como empresa, burocracia, democracia, cultura, arena política e como anarquia. Esse artigo foi classificado no tema "teorias organizacionais". O outro é de Costa e Salm (2006), o trabalho deles buscou, com base nas teorias da Velha Administração Pública, do Novo Negócio Público e do Novo Serviço Público, investigar a percepção que o professor tem de si como funcionário público.

Conforme mostrou o Gráfico 1, os temas mais citados referem-se às políticas educacionais. No total, 13 artigos analisaram o aspecto do investimento e do financiamento da educação. Parte desses artigos foi classificada também nos temas relativos à desigualdade e à qualidade do ensino. Isso se deve ao fato de que os principais desafios educacionais brasileiros não podem prescindir de maior aporte de recursos financeiros e que nem tudo pode ser resolvido apenas no âmbito da gestão ou da avaliação (RICE; SCHWARTZ, 2008). Esses artigos avaliam a eficácia dos fundos de manunteção da educação (FUNDEF e FUNDEB), analisam a capacidade desses fundos de prover um valor por aluno capaz de atender às necessidades educacionais para a oferta da educação de qualidade, abordam a questão dos baixos salários dos professores com formação superior em relação a outros profissionais de mesmo nível de formação, o nível de investimento dos entes federativos em educação, o impacto do investimento no nível de escolarização da população e conexões entre o gasto público em educação e a dinâmica eleitoral e partidária. Há ainda, um trabalho que discute as limitações do uso de cálculos de taxas internas de retorno (TIR) como método orientador de políticas de in- 
vestimentos em educação que conclui que não necessariamente haveria a necessidade de maiores investimentos em educação no Brasil, mas sim de maior clareza de como e onde investir e de políticas mais articuladas entre si (KLEIN, 2008).

O outro tema mais citado em políticas educacionais nos eventos refere-se à desigualdade socioeconômica e à equalização das oportunidades educacionais. Os artigos sobre esse tema tratam de assuntos como: a relação entre renda per capita municipal e variáveis educacionais (evidencia que quanto maior o nível de educação, maior a renda do município); as ações das redes públicas de ensino para lidar com a diversidade socioeconômica $e$ cultural dos alunos; a forma de atendimento das crianças provenientes de famílias de situação desfavorável e que apresentam dificuldades de aprendizagem; a violência que impõe desafios pedagógicos e administrativos e ao cotidiano das escolas; a importância de elementos da infraestrutura escolar como laboratório de informática para alunos de origem socioeconômica desfavorecida como forma de preparação para o mundo do trabalho; a educação para as comunidades indígenas; e os programas de redistribuição de renda associado à frequência escolar dos filhos dos beneficiados como indutor da produção de igualdades de oportunidades.

Os nove artigos sobre avaliação e qualidade do ensino tratam sobre a necessidade de maior aporte de recursos para dotar as escolas da infraestrutura necessária, bem como para atrair bons profissionais e remunerar bem os professores, a eficácia do SAEB para avaliação da política educacional, e a análise comparada da realidade educacional do Brasil com países que superaram desafios semelhantes aos brasileiros. Além disso, há trabalhos sobre a percepção de qualidade de atores específicos como funcionários, coordenadores de projeto e secretários de educação. Uma questão exposta é o problema da descontinuidade gerado pelos ciclos político-eleitorais que acabam afetando potenciais resultados de longo-prazo.

A onda de descentralização das políticas sociais ocorridas na década de 1990 foi analisada no tema "Descentralização". Os cinco artigos referentes a esse assunto abordam principalmente assuntos relacionados à percepção dos gestores escolares, aos impactos da descentralização, à autonomia e à necessidade da maior articulação entre os diferentes entes federativos $e$ entre comunidade e poder público.

Por fim, o artigo de Gonçalves, Gonçalves e Augusto (2004) faz extensa revisão em periódicos das áreas de Educação, História, Administração, 
Economia e Ciências Sociais sobre o tema Estado e educação no período de 1971 e 2000, e os artigos de Campos e Cruz (2007) e de Gonçalves Júnior e Simielli (2007) abordam aspectos do tema "Garantia do direito à educação" dentro dos aspectos já tratados sobre desigualdade social e qualidade do ensino. Já Prado e Cruz (2006) fazem uma revisão sobre as influências da Nova Gestão Pública sobre a reforma da educação no Reino Unido com vista a produzir insights sobre a temática administração da educação no Brasil.

\section{Considerações Finais}

A oferta da educação, por assumir um caráter de bem público, tem imposto desafios aos governos para a administração das instituições de ensino e implementação de políticas públicas para o adequado funcionamento do sistema educacional, a fim de potencializar a geração dos resultados (sociais, econômicos, civis e culturais, para os índivíduos e para as coletividades) esperados da educação na sociedade contemporânea. Em vista disso, este artigo analisou a contribuição dos EnANPADs e EnAPGs no período de 1997 a 2009 para as pesquisas, as reflexões $e$ as discussões sobre administração $e$ políticas públicas da educação básica.

Alguns pontos sumarizam as conclusões da análise dos artigos selecionados:

a) Embora haja um crescimento no número de trabalhos a partir de 2006, as pesquisas sobre a educação pública de nível básico ainda têm ocupado um espaço modesto nos anais dos eventos em questão, o que sugere que trata-se de um tema pouco pesquisado nas pós-graduações em Administração no Brasil.

b) Há indícios de que poucas instituições mantêm linhas ou grupos de pesquisas e disciplinas que incentivem a pesquisa do tema. $\mathrm{O}$ que pode ser inferido a partir da grande concentração de trabalhos oriundos de algumas instituições como EBAPE/FGV, EAESP/ FGV; Fundação João Pinheiro, USP, UFRGS e PUC-PR.

c) Em decorrência do fato anterior, a produção acadêmica do tema se concentra, em quase $90 \%$ dos casos, nas regiões Sudeste e Sul.

d) A análise dos autores denota uma quase inexistência de pesquisadores que se dedicam ao tema de forma continuada em grupos de 
pesquisa. Apenas dois autores apresentaram uma produção contínua sobre o tema nos eventos.

e) Embora a maior parte dos artigos não tenha relação temporal muito estreita com os acontecimentos mais marcantes da política educacional brasileira no período, alguns trabalhos analisaram os cenários de algumas políticas e avaliaram as repercussões de outras, principalmente no caso dos fundos de manutenção e das avaliações de ensino.

f) As pesquisas apresentadas têm, em maior proporção, caráter exploratório ou descritivo, são qualitativas e utilizam técnicas de estudo de caso. O número de estudos quantitativos com uso de técnicas estatísticas e econométricas também é expressivo.

g) No âmbito da ANPAD, as discussões sobre a gestão e as políticas da educação básica acontecem preferencialmente na divisão de administração pública. É pequena a produção sobre teorias, estratégias e técnicas para a educação nas outras divisões.

h) A produção sobre administração se refere basicamente a instrumentos de gestão oriundos do mundo corporativo aplicados às organizações de ensino. $\mathrm{O}$ foco das pesquisas sobre gestão difere dos assuntos mais pesquisados nos programas de pós-graduação em Educação.

i) A produção sobre política é maior, se comparada aos trabalhos sobre gestão, e aborda, primordialmente, os aspectos do financiamento e do investimento em educação, a desigualdade socioeconômica e a equalização das oportunidades educacionais.

Como esta análise partiu da premissa de que os eventos analisados são representativos dos temas pesquisados nos programas de pós-graduação no país, os resultados revelam um quadro de pouco interesse sobre administração e políticas públicas da educação básica.

Considerando que as organizações públicas educacionais também se envolvem num processo que visa utilizar recursos para maximizar os resultados esperados, ou seja, é uma área fecunda para atuação de administradores no planejamento, organização, formulação de estratégias e avaliação de instituições e sistemas de ensino, acredita-se que a administração da educação também seja tema pertinente aos programas de pós-graduação em admi- 
nistração, inclusive em esforços multidisciplinares com outras áreas do conhecimento como a Educação, Economia, Ciências Sociais, etc. No entanto, no atual estágio, a produção de conhecimento apresentado do EnANPAD e do EnAPG é modesta.

É certo que, em diversos países, a gestão das organizações e os sistemas de ensino público têm sido amplamente pesquisados nas faculdades de educação. Talvez a orientação sócio-histórica de base marxista, fenomenológica, existencialista e anarquista adotada nas pesquisas dos programas de pós-graduação em Educação no Brasil (PEREIRA; ANDRADE, 2005; SANDER, 2007) seja um óbice para a aproximação entre as duas áreas (Administração e Educação) em torno de temas comuns (administração e política da educação). Talvez essa seja uma das causas do pouco interesse por pesquisas em gestão da educação, verificado nos anais dos eventos em foco. Essa suposição poderia ser investigada em trabalhos futuros.

Acredita-se que as pesquisas das escolas de administração podem colaborar mais para o avanço das práticas administrativas nas escolas em parceria com os profissionais da área pedagógica (professores e coordenadores de ensino), mas, sobretudo, nas secretarias e superintendências de ensino que se encarregam da gestão das redes de escolas geridas pelos governos municípais ou estaduais. Nesse ponto, as demandas por um processo racional para coordenar esforços de pessoas e para utilizar recursos (PARO, 2002) nos órgão gestores das redes públicas de ensino são tão graves como em qualquer outra grande corporação pública ou privada. As Secretarias Estaduais, em especial, têm o desafio de gerir grandes números. Segundo o Censo Escolar de 2007, em alguns casos, como nas redes estaduais da Bahia, Goiás, Maranhão, Pará, Paraíba, Pernambuco, Paraná, Rio de Janeiro, Santa Catarina e Rio Grande do Sul, as redes são compostas por mais de 1.000 escolas. Em Minas Gerais esse número ultrapassa 4.000 e em São Paulo são mais de 6.200 escolas. Nessas organizações há espaço para o desenvolvimento de técnicas administrativas oriundas de todas as grandes áreas da Administração (Recursos Humanos, Administração Orçamentária e Financeira, Produção e Administração de Materiais e Patrimônio, Marketing e Comunicação, etc.). Por isso acredita-se que as escolas de administração poderiam produzir conhecimento para a administração da educação para além da aplicação das técnicas e dos modelos adotados nas organizações orientadas tão somente pela eficiência e pelo lucro e não apenas se restringir a eles, como foi verificado na maior parte dos artigos analisados sobre gestão, como forma de evitar os efeitos indesejados da simples transposição das práticas admi- 
nistrativas das empresas no setor público (SANDER, 2007; PAULA, 2005). Assim, diante da relevância e dos retornos sociais que a pesquisa sobre administração da educação pode gerar para o país, essa prática deveria ser mais estimulada no âmbito das escolas de administração.

Todavia, a produção sobre as políticas da educação nos eventos é mais ampla e tem empreendido esforços multidisciplinares. Isso fica evidente na abordagem de assuntos como financiamento, investimento, desigualdade social, avaliação de políticas, etc., além de autores e técnicas de pesquisa adotados em outras áreas de conhecimento como Educação, Economia, Sociologia e Ciência Política. Apesar de ser em maior número entre os artigos selecionados na revisão e serem poucos se comparados ao total de artigos apresentados nos eventos, os trabalhos sobre política se mostram coerentes com os principais desafios da educação brasileira na atualidade (equalização das oportunidades educacionais para a população independente da origem socioeconômica, universalização do acesso, e a oferta do ensino em condições de qualidade) apresentados por Souza (2007), Castro e Werle (2004) e Oliveira (2006).

Trabalhos futuros poderiam também investigar a existência, a intensidade e os temas de interesse em administração pública nos eventos da ANPAD com vista a investigar a relevância da administração pública nos programas de pós-graduação em administração no Brasil. Isso porque, como foi verificado que a pesquisa sobre educação se concentra na divisão de administração pública da ANPAD e em instituições com tradição em administação pública como a FGV e a Fundação João Pinheiro, talvez seja possível que o pequeno interesse na pesquisa sobre administração e política da educação seja apenas o corolário de uma participação modesta da pesquisa em administração pública no âmbito dos programas de pós-graduação em administração em relação a outras áreas desse ramo do conhecimento.

\section{Agradecimentos}

Agradecemos a CAPES/INEP/MEC e FAPESP pelo apoio financeiro à pesquisa. 


\section{Public Administration and Policies on Education: a systematic review of the scientific production of EnANPAD and EnAPG between 1997 and 2009}

\section{Abstract}

In view of the consensus about the relevance of education for social and economic development, it is believed that the administration of schools and organizations that are responsible for managing educational networks is a prominent subject for research in Administration. In this context, the aim of this article is to describe the contribution of the EnANPAD and of the EnAPG for the output of knowledge about Administration and Public Policies of basic education. For that purpose, a systematic review of the annals of these events in the period between 1997 and 2009 was conducted. A total of 49 articles were analyzed by means of a protocol that allowed the description of: papers characteristics (temporal distribution of publications and author characteristics); methodological aspects (approach and typology of research from academic/scientific points of view); and themes addressed. It was observed that the output is distributed heterogeneously in time; the majority of authors are linked to institutions in the Brazilian South and Southeast; there is a balance between descriptive and exploratory studies; and there are few inferential studies. The qualitative approach is predominant $(55 \%)$; however, there is a representative number of quantitative papers (35\%). Regarding the themes, it was verified that $81.6 \%$ of the articles refer to four main topics: socioeconomic inequality, educational financing, educational quality and managerial instruments.

Key words: Education. Administration. Public Policies. Systematic Review.

\section{Referências}

ALMEIDA, J. R. P. História da instrução pública no Brasil: 1500 a 1889. São Paulo: INEP-MEC, 1989.

BRASIL. Constituição da República Federativa do Brasil de 1988.

Disponível em: <http://www.planalto.gov.br/ccivil_03/constituicao/

Constitui\%E7ao_Compilado.htm>. Acesso em: 22 jul. 2011. 
BRASIL. Emenda Constitucional n. 59, de 11 de novembro de 2009, Acrescenta $\S 3^{\circ}$ ao art. 76 do Ato das Disposições Constitucionais Transitórias para reduzir, anualmente, a partir do exercício de 2009, o percentual da Desvinculação das Receitas da União incidente sobre os recursos destinados à manutenção e desenvolvimento do ensino de que trata o art. 212 da Constituição Federal, dá nova redação aos incisos I e VII do art. 208, de forma a prever a obrigatoriedade do ensino de quatro a dezessete anos e ampliar a abrangência dos programas suplementares para todas as etapas da educação básica, e dá nova redação ao $\S 4^{\circ}$ do art. 211 e ao $\S 3^{\circ}$ do art. 212 e ao caput do art. 214, com a inserção neste dispositivo de inciso VI. Disponível em: <http://www6.senado.gov.br/legislacao/ListaPublicacoes.action?id=260049>. Acesso em: 22 Jul. 2010.

CAMPOS, B; CRUZ, B. Impactos do FUNDEB sobre a qualidade do ensino básico público: uma análise para os municípios do estado do Rio de Janeiro. Anais... Rio de Janeiro, XXXI EnANPAD, 2007.

CASANOVA, P. G. As novas ciências e as humanidades: da academia à política. São Paulo: Boitempo, 2006.

CASASSUS, J. A Escola e a desigualdade. Brasília: INEP/Editora Plano, 2002.

CASTRO, M. L. S.; WERLE. Estado do conhecimento em Administração da Educação: uma análise dos artigos publicados em periódicos nacionais 19822000. Ensaio: Aval. Pol. Públ. Educ., Rio de Janeiro, v. 12, n. 45, p. $1.045-$ 1.064, out./dez. 2004.

\section{CLARKE, M. Cochrane Reviewers' Handbook 4.1. Review Manager} (RevMan). Oxford, England: The Cochrane Collaboration, 2001. Disponível em: $<$ http://www.cochrane.dk/cochrane/handbook/handbook.htm>. Acesso em: 27 jul. 2011.

COSTA, K. C. O; SALM, J. F. A percepção do professor estadual como funcionário público: cumpridor de regras, empreendedor ou servidor público?Anais... Salvador, XXX EnANPAD, 2006.

FADUL, E. M. C.; SILVA, M. A. M. Limites e possibilidades disciplinares da administração pública e dos estudos organizacionais. RAC, Curitiba, v. 13, n. 3, jul. 2009. 
FOUREZ, G. A construção das ciências: introdução à filosofia e à ética das ciências. São Paulo: UNESP, 1995.

FUENZALIDA, E. R. Criterios de análisis de la calidad en el sistema escolar y sus dimensiones. Revista Iberoamericana de Educación, Madrid, n. 5, p. 45-65, mai./ago. 1994.

GONÇALVES, N. G.; GONÇALVES, S.; AUGUSTO, P. O. M. Sobre a relação estado e educação na produção acadêmica brasileira (1971-2000): temas, críticas e expectativas. Anais... Curitiba, XXVIII EnANPAD, 2004.

GONÇALVES JUNIOR, O. SIMIELLI, L. E. Políticas públicas em educação: lições do caso sul-coreano. Anais... Rio de Janeiro, XXXI EnANPAD, 2007.

HUITRÓN, I. L. Eqüidade na alocação de recursos em educação. In: Eqüidade e Financiamento da Educação na América Latina, Brasília: UNESCO, 2002.

JESUS, J. S.; SANTOS, J. N. A gestão participativa nas escolas públicas municipais de salvador. Anais... Rio de Janeiro, XXXI EnANPAD, 2007.

KLEIN, F. A. Taxas de retorno, custos e investimentos em educação no Brasil e na América Latina. Anais... Salvador, III EnAPG, 2008.

KLIKSBERG, B. América Latina: uma região de risco: pobreza, desigualdade e institucionalidade social. UNESCO, 2002.

OLIVEIRA, R. P. Estado e Política Educacional no Brasil: desafios do século XXI. Tese de Livre-docência. Faculdade de Educação. Universidade de São Paulo, São Paulo, 2006.

OLIVEIRA, R. P.; ARAÚJO, G. C. Qualidade do ensino: uma nova dimensão da luta pelo direito à educação. Rev. Bras. Educ., Rio de Janeiro, n. 28, p. 5-23, jan./abr. 2005.

OSBORNE, D.; GAEBLER, T. Reinventando o governo. Brasília: MH Comunicação, 1995.

PARO, V. H. Administração escolar: introdução crítica. 11. ed. Campinas: Cortez, 2002.

PAULA. A. P. P. Por uma nova gestão pública - limites e potencialidades da experiência contemporânea. Rio de Janeiro: FGV, 2005. 
PEREIRA, G. R. M.; ANDRADE M. C. L. A construção da administração da educação na RBPAE (1983-1996). Educação e Sociedade, Campinas, v. 26, n. 93, set./dez. 2005.

PINHO, A.; GÓIS, A.; TAKAHASHI, F. Vértice, de SP, é melhor do país pela $1^{\text {a }}$ vez. Folha de São Paulo, São Paulo, 19 jul. 2010. Especial Educação, p. 8.PRADO, M. A.; CRUZ, B. P. A. A Nova Administração Pública e a Educação: a competição administrada e o gerencialismo no Reino Unido. Anais... São Paulo, II EnAPG, 2006.

REINALDO, M. Z. L.; BRITO, L. M. P. Avaliação da contribuição do conselho escolar para melhoria da gestão da escola Vicente Fialho. Anais... Salvador, III EnAPG, 2008.

RICE, J. K.; SCHWARTZ, A. E. Toward an understanding of productivity in education. In: LADD, H. F.; FISKE, E. B. Handbook of research in education finance and policy. New York: Routledge, 2008.

RIBEIRO, V. M.; RIBEIRO, V. M.; GUSMÃO, J. B. Indicadores de qualidade para a mobilização da escola. Cadernos de Pesquisa, São Paulo, v. 35, n. 124, jan./abr., 2005.

ROTHSTEIN, R.; JACOBSEN, R. Educational goals: a public perspective. In: LADD, H. F.; FISKE, E. B. Handbook of research in education finance and policy. New York: Routledge, 2008.

SANDER, B. Administração da Educação no Brasil: genealogia do conhecimento. Brasília: Liber, 2007.

SOBREIRA, R.; CAMPOS; B. C. Disparidades regionais na educação básica brasileira: uma análise da proposta de emenda constitucional do FUNDEB. Anais... Salvador, XXX EnANPAD, 2006.

SOARES, J. F et al. (Coord.) Escola Eficaz: um estudo de caso em três escolas da rede pública de ensino do Estado de Minas Gerais. Belo Horizonte: UFMG, 2002. Disponível em: < http://www.fae.ufmg.br:8080/game/eficaz.pdf>. Acesso em: dia $1^{\circ}$ dez. 2006.

SOUZA, C. Pesquisa em Administração Pública no Brasil: uma agenda para o debate. Revista de Administração Pública, Rio de Janeiro, v. 32, n. 4, p. 45-61, jul./ago. 1998. 
SOUZA, A. R. Perfil da gestão escolar no Brasil. Tese (Doutorado) Educação: História, Política, Sociedade, PUC-SP, São Paulo, 2007.

SOUZA, S.; PRADO, V. J. Imagens da escola como organização: uma análise comparativa entre o modelo burocrático e a anarquia organizada através de metáforas. Anais... São Paulo, XXXIII EnANPAD, 2009.

SUCUPIRA, L. A. et al. Implantação de uma gestão participativa nas creches do programa nova baixada. Anais... Rio de Janeiro, XXXI EnANPAD, 2007.

TEDESCO, J. C. Prólogo. In: Eqüidade e financiamento da educação na América Latina. Brasília: UNESCO, 2002.

THIMOTEO, F. E. P.; GOMES; E. G. M. Descentralização, financiamento e desempenho escolar: avaliação do FUNDEF à luz do desempenho no SAEB. Anais... Campinas, XXV EnANPAD, 2001. 